\title{
The Effect of Forced Air Warming System on Post Anesthetic Recovery of Patients Undergoing Major Abdominal Surgeries
}

\author{
Gehan Mohamed Desoky, Lecturer \\ Medical Surgical Nursing, Faculty of Nursing, Alexandria University
}

\begin{abstract}
Patients undergoing major abdominal surgeries are at increased risk for hypothermia during the intraoperative phase of the surgical experience. Forced air warming (FAW) during surgery is a safe and effective intervention used to reduce hypothermia and improve the post anesthetic recovery of patients. Objective: Assess the effect of forced air warming system on post anesthetic recovery for patients undergoing major abdominal surgeries. Setting: The study was conducted at the general operating rooms and recovery rooms at Alexandria Main University Hospital. Subjects: They comprised a convenience sample of 40 patients undergoing major abdominal surgeries. Patients were classified into the control and study groups ( $n=20$ in each group). Tool: One tool was used for data collection, to collect the necessary data related to effect of forced air warming system on occurrence of hypothermia, post anesthesia recovery and postoperative shivering, for patients undergoing major abdominal surgeries. Results: The results of the current study showed that there was a statistically significant difference in patient's core temperature and post anesthesia recovery $(P<0.05)$ between the control and study groups. Conclusion: It was concluded that, using the forced air warming system is effective in preventing hypothermia and earlier patient's recovery from anesthesia. Recommendations: Forced air warming should be available in all operating rooms and recovery rooms, to be used especially for major surgeries.
\end{abstract}

Keywords: Forced air warming; Post anesthetic recovery; Major abdominal surgery.

\section{Introduction}

Patients undergoing major abdominal surgery with general anesthesia exposed to adverse outcomes associated with disturbances in thermoregulation during the intraoperative phase of the surgical experience $^{(1)}$. Unintended hypothermia is a common incident in the immediate postoperative period. It affects more than $70 \%$ of patients undergoing surgery and anesthesia $^{(2-4)}$.

Hypothermia is defined as core body temperature less than $36^{\circ} \mathrm{C}(96.8 \mathrm{~F})$, and may be classified as mild $\left(35.0^{\circ} \mathrm{C}-35.9^{\circ} \mathrm{C}\right)$, moderate $\left(34.0^{\circ} \mathrm{C}-34.9^{\circ} \mathrm{C}\right)$ and severe $\left(\leq 33.9^{\circ} \mathrm{C}\right)^{(5)}$. Hypothermia is known to increase postoperative complications; it can reduce platelet function, impair enzymes of the coagulation pathway, increases surgical blood loss and transfusion requirements, prolong the duration of action of anesthetic drugs, delays post-anesthetic recovery, and lead to occurrence of shivering ${ }^{(6,7)}$. So, it is important to do all efforts to prevent hypothermia in the intraoperative period.

Hypothermia results from a combination of anesthetic impaired thermoregulation and exposure to cold operating theater. In addition to, evaporation from exposed body cavities and from respiratory epithelium, infusion of cold fluids and inhalation of cold gases. Also there are some factors that contribute to the increased risk of hypothermia including extremes of age, gender (female), length and type of surgery, preexisting conditions, and type of anesthesia used ${ }^{(8-11)}$.

To avoid this unintended hypothermia, several different types of active warming systems are used to transfer heat to the body of the patient through the skin, immediately before, during, and after surgery. Measures to prevent intraoperative hypothermia include, using forced air-warming system to prevent or treat hypothermia in surgical patients. It is safe and recommended for 
use during general anesthesia in clinical guidelines, which rapidly increases the mean body temperature. Forced air warming has been shown to maintain normothermia even during major operations ${ }^{(12-14)}$. In addition to, maintaining environmental temperature within 21-24 ${ }^{\circ} \mathrm{C}^{(15)}$, and warming intravenous fluids to $37{ }^{\circ} \mathrm{C}^{(16,17)}$.

Temperature monitoring provides an early detection of hypothermia. The most accurate site to obtain core body temperature is tympanic membrane, because it has abundant arterial blood supply from branches of external carotid artery, and shares blood supply with the hypothalamus. Tympanic temperature measurements seem to be the best alternative to rectal and infrared skin measurements ${ }^{(18)}$.

All nursing care providers are responsible for warming surgical patients and preventing hypothermia in the patient undergoing surgery. Especially operating room nurses, nurse anesthetists, post anesthesia care unit nurses, critical care nurses and medical surgical nurses who manage it in postoperative period. Preventing hypothermia reduces both length of hospital stay after surgery and post anesthesia care unit stay. So, the nurse must do all efforts in maintenance of patient's temperature in the intraoperative period, because these will reduce both the nurse's time and effort in caring for surgical patient in the postoperative period.

\section{Aim of the Study}

The study aims to assess the effect of forced air warming system on post anesthetic recovery for patients undergoing major abdominal surgeries.

\section{Research Hypothesis:}

The forced air warming system is effective in earlier post anesthetic recovery for patients undergoing major abdominal surgeries.

\section{Materials and Method}

\section{Materials}

Design: A quasi experimental study design was used to conduct this study.

Setting: The study was conducted in the general operating rooms and recovery rooms at Alexandria Main University Hospital.

Subjects: The subjects of this study were comprised of a convenience sample of 40 adult patients, assigned equally into study and control groups, 20 patients in each group.The study sample was estimated based on Epi info program, which used to estimate the sample size using the following parameters:

- $\quad$ Population size $=110$.

- Expected frequency $=50 \%$.

- $\quad$ Margin of error $=10 \%$.

- Confidence coefficient $=95 \%$.

- $\quad$ Minimum sample size $=40$.

The patients' inclusion criteria were:

- Age ranging from 20-60 years.

- Scheduled for major abdominal surgery (abdominal cavity exposed for three hours or more).

- With normal preoperative temperature.

- The patient received general and/or combined anesthesia (general and regional).

Tool: One tool was used, it was developed by the researcher after reviewing of related literature $^{(18-20)}$, to collect the necessary data related to effect of forced air warming system on occurrence of hypothermia, post anesthesia recovery and postoperative shivering. It includes four parts:

Part (1): Sociodemographic and clinical data:

A. Sociodemographic data: It includes age, sex, marital status, level of education, occupation and medical history.

B. Clinical data: It includes diagnosis, type of surgery, duration of surgery and type of anesthesia either general or combined (regional + general). 
Part (2): Hypothermic assessment sheet:

- Core body temperature was taken in the day before surgery as a baseline data and for later comparison in the intra and postoperative period, by using tympanic thermometer ${ }^{(18)}$.

- Ambient temperature was measured during the intraoperative period.

Part (3): Post anesthesia recovery scores: It was developed by Phillips in $2004^{(19)}$, to assess post anesthesia recovery scores it includes:

\begin{tabular}{|c|c|}
\hline - Consciousness: & \\
\hline - Fully awake & 2 \\
\hline - Arousable & 1 \\
\hline - Not responding & 0 \\
\hline - Respiration: & \\
\hline $\begin{array}{l}\text {-Able to breathe deeply and cough } \\
\text { freely }\end{array}$ & 2 \\
\hline -Dyspnea and shallow breathing & 1 \\
\hline - Dyspnea and stridor & 0 \\
\hline - Circulation: & \\
\hline $\begin{array}{l}\text { - Blood pressure } \pm 20 \% \text { of pre } \\
\text { anesthesia level. }\end{array}$ & 2 \\
\hline $\begin{array}{l}\text { - Blood pressure } \pm 20-50 \% \text { of pre } \\
\text { anesthesia level. }\end{array}$ & 1 \\
\hline $\begin{array}{l}\text { Blood pressure } \pm>50 \% \text { of pre } \\
\text { anesthesia level. }\end{array}$ & 0 \\
\hline - Color: & \\
\hline - Pink $\mathrm{SaO}_{2}>95 \%$ & 2 \\
\hline - Pale and dusky $\mathrm{Sao}_{2} 90-94 \%$ & 1 \\
\hline - Cyanotic $\mathrm{SaO}_{2}<90 \%$ & 0 \\
\hline - Activity: & \\
\hline - Able to move voluntarily & 2 \\
\hline - Able to move on command & 1 \\
\hline - Unable to move & 0 \\
\hline Total score & \\
\hline
\end{tabular}

The total score of post anesthesia recovery $=10$

Part (4): Shivering scale:

It was developed by Holzclow since $1990^{(\mathbf{2 0})}$, to assess incidence, duration and severity of shivering, it includes:

\begin{tabular}{|l|l|}
\hline - No shivering & Zero \\
\hline - Palpable masseter contraction. & 1 \\
\hline - Face and neck contractions. & 2 \\
\hline - Mild contractions of neck and trunk. & 3 \\
\hline $\begin{array}{l}\text { - Strong generalized contractions } \\
\text { including extremities. }\end{array}$ & 4 \\
\hline
\end{tabular}

\section{Method}

- An official letter from the Faculty of Nursing was submitted to the director of the chosen setting to obtain permission for data collection, after explanation of the aim of the study.

- Tool was developed by the researcher after reviewing of the current related literature $^{(18-20)}$.

- The study tool was revised by five experts in the field medical surgical nursing to test the tools for content validity, completeness and clarity of the items, and necessary modifications were carried out.

- Reliability of the tool was tested using Cronbach's Alpha where $\mathrm{r}=0.87$.

- A pilot study was initially carried out on 5 patients prior to the actual data collection to assess clarity and applicability of the tools and to identify the difficulties that may be encountered during data collection. These patients were excluded from the study subjects.

- The study subjects meeting the inclusions criteria were assigned randomly into one of the two groups (control and study groups).

- The first group (control group) was received the routine care in relation to warming in the intra and postoperative periods.

- The second group (study group) received the following interventions in the intraoperative period:

- The investigator warmed the patient using forced air warming device (It consists of a disposable blanket to cover the patient as a heat source; the blanket contains holes to allow warm air to flow between the patient and the blanket). The device has 3 settings low 30-34 ${ }^{\circ} \mathrm{C}$, medium $36-40{ }^{\circ} \mathrm{C}$ and high $42-46^{\circ} \mathrm{C}$. The temperature of the device was adjusted to maintain the 
baseline core body temperature using the medium setting, to avoid over warming of the patient. It was used immediately after receiving anesthesia (either combined (general + epidural) or general anesthesia only) and throughout the surgery, and in the immediate postoperative period until return to baseline temperature. The blanket used in the intraoperative period was applied on the upper body of the patient (chest, neck and arms). The blanket was placed in contact with patient's gown, and then the patient was covered with the surgical drape.

- The investigator warmed intravenous solutions used in intraoperative period to $37-38^{\circ} \mathrm{C}$ by inserting the intravenous solution bottle in hot water bath then the bottle was attached to intravenous warmer (it is an electrically powered, dry heat warmer which supplies external heat to plastic tubing incorporated in intravenous administration sets. The intravenous tube set is placed in the "S" shaped channel in the aluminum heating plate. The intravenous solutions and blood were maintained warm throughout the surgery.

- The environmental temperature was maintained within $21-24^{\circ} \mathrm{C}$ by air conditioner before receiving anesthesia and throughout the surgery.

- For both groups in the intraoperative period, the following measures were assessed:

- Tympanic temperature every 30 minutes.

- The duration of surgery was calculated.

- For both groups in the postoperative period, all patients were assessed for the following parameters:

- Every 15 minutes for core body temperature using tympanic thermometer until return to baseline temperature.

- Every 10 minutes for recovery time using post anesthesia recovery score until the recovery score reach 10 (using part 3 of the tool).

- The occurrence of shivering, if shivering occurred the patient was observed for onset, duration, severity and frequency of shivering using shivering scale by continues observation (using part 4 of the tool).

\section{Ethical considerations:}

- Patient's written approval to participate in the study was obtained, after explaining the purpose of the study.

- Privacy of the patients was maintained.

- Confidentiality of the collected data was secured.

- Patient's right to withdraw at any time of research participation was considered and respected.

\section{Statistical Analysis}

- Statistical analysis was performed using Statistical Package for the Social Sciences Version 16.0 for windows (SPSS Inc. UK Ltd, Working).

- Descriptive measures included: Count, percentage, mean, standard deviation, minimum and maximum.

- Statistical analysis was conducted to include these tests (Chi-square for analysis of qualitative variables, student's t-test to compare 2 arithmetic means, and paired t-test to determine the level of significance for change in each group).

- The level of significance selected for this study was $\mathrm{P}$ equal to or less than 0.05 . 


\section{Results}

Table (1) shows distribution of the control and study groups as regards sociodemographic and clinical data. Regarding patient's age, the result revealed that, the mean value of age of the patients in control group was $45.500 \pm 4.0972$ years, while in the study group the mean value was $45.9000 \pm 4.1915$ years. In relation to sex, the majority of patients in the control and study groups were males $(70 \%$ and $90 \%$ respectively).

Concerning past medical history, nearly half of patients in the control and study groups $(45 \%, 50 \%$ respectively) had no associated disorder. However, cardiovascular, hypertension, liver and respiratory were the associated disorders among the rest of the participated patients.

Findings showed that, the highest diagnosis among the control group was portal hypertension $(25 \%)$. While in the study group $60 \%$ of patients suffering from portal hypertension, abdominal mass and cancer liver equally.

It was observed that, in the control group $25 \%$ made Warren's operation, whereas an equal percentage $10 \%$ made spleenoectomy, gastrectomy and nephrectomy. While in the study group $60 \%$ of patients made Warren's operation, abdominal exploration and liver resection equally.

It was found that, the patients who received combined anesthesia were more than the patients who received general anesthesia in both control and study groups. There was no statistical significant difference between both groups $\left(\mathrm{X}^{2}=0.8967\right.$, $\mathrm{P}=0.96833$ )

The table shows that, the duration of surgery ranged from 3-4.5 hours in both control and study groups, the mean value in the control group was $3.70 \pm 0.50$ hours, while in the study group was $3.70 \pm 0.59$ hours. There was no statistical significant difference between both groups $(\mathrm{Z}=0.7737$, $\mathrm{P}=0.4391$ ).
Table (2) illustrates comparison between the control and study groups in relation to core body temperature during the perioperative period. There was no statistical significant difference between both groups in preoperative period. While there was statistical significant lowering of core body temperature in the control group than the study group during the whole intraoperative and postoperative periods starting from the beginning of operation till $60 \mathrm{~min}$ postoperative $(\mathrm{p}=0.0000)$.

Table (3) shows comparison between the control and study groups as regards time to return to base line temperature (minutes). Analysis of data revealed that, the mean value of time to return to baseline temperature was higher in control group $187.50 \pm 25.78$ minutes compared with the study group $45 \pm 13.00$ minutes. There was a statistical significant difference between both groups in relation to time to return to baseline temperature $(\mathrm{Z}=6.4337, \mathrm{P}=0.000)$.

Table (4) elaborates comparison between the control and the study groups as regards post anesthesia recovery score in postoperative period. All patients in the study group achieved the highest post anesthesia recovery score (9-10), out of 10 which is the maximum post anesthesia recovery score after 30 minutes, compared to patients in the control group only 5 (25\%) of them achieved post anesthesia recovery score (9-10) after 90 minutes. There was a statistical significant difference between both groups after 10, 20, 30 minutes ( $\mathrm{P}=0.047,0.0188,0.003$ respectively).

Table (5) illustrates incidence, severity, onset, duration and frequency of shivering among the control and the study groups. Concerning the incidence of shivering, $75 \%$ of the control group suffered from shivering compared to $25 \%$ in the study group. In relation to severity of shivering the highest shivering score in the control group was 3 compared to 2 in the study group, out of 3 which is the maximum shivering score. There was a statistical significant difference 
between both groups in relation to incidence of shivering $(\mathrm{Z}=8.528, \mathrm{P}=0.0018)$.

In addition, the mean duration of shivering in the control group was $10.56 \pm 3.6855$ minutes and the range was between 5-15 minutes. While in the study group the mean duration was 5.76 \pm 5.866 minutes and the range was between 5-7 minutes. There was a statistical significant difference between both groups $(Z=3.4657$, $\mathrm{P}=0.0144$ ). Finally the table reveals that, the mean frequency of shivering in the control group was $6.879 \pm 2.870$. While in the study group was $3.678 \pm 0.980$. There was a statistical significant difference between both groups $(\mathrm{Z}=4.4789, \mathrm{P}=0.0024)$.

\section{Discussion}

Hypothermia has profound effects on every body systems and may result in life threatening problems if not recognized and treated promptly. It can cause adverse cardiovascular, hematologic, immunologic, metabolic and neurologic effects. Higher postoperative complication rates have been reported with mild hypothermia. Mild hypothermia significantly increases blood loss, and only $1.9{ }^{0} \mathrm{C}$ core hypothermia triples the incidence of surgical wound infection and increases duration of hospitalization by $20 \%$ and increase the duration of recovery from anesthesia ${ }^{(21,22)}$. To prevent the inadvertent perioperative hypothermia, it is recommended for to use forced air warming (FAW), which is a safe and effective intervention for the prevention of hypothermia ${ }^{(12-14)}$.

The current study was conducted on patients undergoing major abdominal surgeries, to investigate the effect of forced air warming system on post anesthetic recovery. In the present study, there was no statistical significant difference in sociodemographic data between the control and study groups, regarding age, sex, type of anesthesia, duration and type of surgery.

The most important finding of this study, showed a statistical significant difference between the control and study groups in relation to time to return to baseline temperature, where the duration was significantly shorter in the study group than in the control group. In addition to, the incidence of hypothermia was approximately higher in the control group than in the study group. This may be related to using of forced air warmer device in the study group during the intraoperative and in the immediate postoperative periods, in addition to warming intravenous fluids and the environment during surgery. The forced air warming warmed the patient through two mechanisms; first is prevention of radiative heat loss by covering the cool body surfaces with a warmer cover. Second is prevention of convective heat loss through increasing heat gain when the air is warmer than the skin. So, forced air warmer take the advantage of these two phenomena by producing a flow of warm air across the skin $^{(23)}$.

This result was supported by Shaw A et al $(2017)^{(24)}$, in a recent meta-analysis of eight trials with 1189 participants, they found that forced air warming increased postoperative temperature by $0.36^{\circ} \mathrm{C}$, and reduced risk of hypothermia by $29 \%$.

The result of the current study showed that, the patient recovered from anesthesia more rapidly in the study group than in the control group. This can be explained by, hypothermia decreases the minimal alveolar concentration of anesthetics, potentiates neuromuscular blockade and slows the metabolism of many drugs. Some or all of these factors may have played a role in the prolonged recovery time ${ }^{(25)}$. As the forced air warming is more effective in warming patients and prevents hypothermia occurrence, so it is more effective in faster recovery from anesthesia.

These results stand in line with the findings of Jie et al. (2017) ${ }^{(26)}$, they found that, the forced air warmer device reduced the length of recovery compared hypothermic patients. 
On the other hand, Smith et al. $(1994)^{(27)}$ studied 127 patients undergoing out patient arthoscopic knee procedures lasting less than an hour. Patients were randomly assigned to receive either forced air warming or warm cotton blanket. They found that no statistical significant difference between patients who received either forced air warming or the cotton blanket in relation to reduction in post anesthesia care unit (PACU) stay. These can be explained by the duration of surgery was less than an hour, so the hypothermia was not evident compared with long procedures.

In the present study, the incidence of shivering was nearly triple in the control group than in the study group. Moreover, the severity and duration of shivering was significantly greater in the control group than in the study group. This is in agreement with Kiekkas et al. $(2005)^{(28)}$, they found that most of surgical patients experienced shivering, which was observed primarily in hypothermic patients.

The result of this study was in line with Sultan et al. (2015) $)^{(29)}$ and Yossef (2006) $)^{(30)}$, they found that forced air warming is beneficial in limiting the incidence, magnitude and duration of shivering when used in a prophylactic manner to rewarm patients during intra and postoperative periods.

These results demonstrated the need to put in practice a care protocol aimed at effective interventions for hypothermia prevention. The nurses play an important role, as patient safety and the reduction of complications due to surgical anesthesia are nursing care targets ${ }^{(31)}$. Therefore, prevention of this problem requires intraoperative temperature monitoring, skillful nursing interventions aiming at maintaining patient's temperature and collaborative work with surgical, anesthetic and nursing team members.

\section{Conclusion}

- The patients in the study group return to baseline temperature faster than patients in the control group.

- The patients warmed by forced air warming system (study group) recovered from anesthesia in shorter time than patients in the control group.

- The incidence, severity and duration of shivering were lower in the study group.

\section{Recommendations}

- Forced air warming should be available in all operating rooms and recovery rooms, to be used especially for major surgeries. 
Table (1): Distribution of the control and study groups as regards socio-demographic and clinical data

\begin{tabular}{|c|c|c|c|c|c|}
\hline \multirow{2}{*}{ Socio-demographic and clinical data } & \multicolumn{2}{|c|}{ Control group } & \multicolumn{2}{|c|}{ Study group } & \multirow[t]{2}{*}{ Test } \\
\hline & No & $\%$ & No & $\%$ & \\
\hline $\begin{array}{l}\text { Age (in years) } \\
\text { Range } \\
\text { Mean } \pm \text { SD }\end{array}$ & \multicolumn{2}{|c|}{$\begin{array}{c}30-60 \\
45.500 \\
4.0972 \\
\end{array}$} & \multicolumn{2}{|c|}{$\begin{array}{c}30-60 \\
45.9000 \\
4.1915 \\
\end{array}$} & $\begin{array}{c}Z=0.6324 \\
P=0.73416\end{array}$ \\
\hline $\begin{array}{l}\text { Sex }(\mathrm{n}) \\
\text { Male } \\
\text { Female }\end{array}$ & $\begin{array}{c}14 \\
6 \\
\end{array}$ & $\begin{array}{l}70 \\
30 \\
\end{array}$ & $\begin{array}{c}18 \\
2 \\
\end{array}$ & $\begin{array}{l}90 \\
10 \\
\end{array}$ & $\begin{array}{l}X^{2}=0.7652 \\
P=0.87646\end{array}$ \\
\hline $\begin{array}{l}\text { Medical History } \\
\text { Negative } \\
\text { Cardiac } \\
\text { Hypertensive } \\
\text { Liver } \\
\text { Respiratory } \\
\text { Renal } \\
\end{array}$ & $\begin{array}{l}9 \\
3 \\
2 \\
3 \\
3 \\
0 \\
\end{array}$ & $\begin{array}{c}45 \\
15 \\
10 \\
15 \\
15 \\
0 \\
\end{array}$ & $\begin{array}{c}10 \\
5 \\
1 \\
1 \\
2 \\
0 \\
\end{array}$ & $\begin{array}{c}50 \\
25 \\
5 \\
5 \\
10 \\
0 \\
\end{array}$ & $\begin{array}{c}X^{2}=0.5468 \\
P=0.9128\end{array}$ \\
\hline \begin{tabular}{|l} 
Diagnosis \\
Abdominal mass \\
Portal hypertension \\
Splenomegaly \\
Cancer liver \\
Epigastric mass \\
Renal tumors \\
Pancreatic mass \\
\end{tabular} & $\begin{array}{l}3 \\
5 \\
2 \\
3 \\
2 \\
2 \\
3 \\
\end{array}$ & $\begin{array}{l}15 \\
25 \\
10 \\
15 \\
10 \\
10 \\
15\end{array}$ & $\begin{array}{l}4 \\
4 \\
2 \\
4 \\
1 \\
2 \\
3\end{array}$ & $\begin{array}{c}20 \\
20 \\
10 \\
20 \\
5 \\
10 \\
15\end{array}$ & $\begin{array}{l}X^{2}=0.1026 \\
P=0.12234\end{array}$ \\
\hline \begin{tabular}{|l} 
Type of Surgery \\
Warren's operation \\
Abdominal exploration \\
Spleenoectomy \\
Liver resection \\
Gastrectomy \\
Nephrectomy \\
Pancreatectomy \\
\end{tabular} & $\begin{array}{l}5 \\
3 \\
2 \\
3 \\
2 \\
2 \\
3 \\
\end{array}$ & $\begin{array}{l}25 \\
15 \\
10 \\
15 \\
10 \\
10 \\
15\end{array}$ & $\begin{array}{l}4 \\
4 \\
2 \\
4 \\
1 \\
2 \\
3\end{array}$ & $\begin{array}{c}20 \\
20 \\
10 \\
20 \\
5 \\
10 \\
15\end{array}$ & $\begin{aligned} X^{2} & =0.1566 \\
P & =0.2301\end{aligned}$ \\
\hline \begin{tabular}{|l|} 
Type of anesthesia \\
General \\
Combined \\
\end{tabular} & $\begin{array}{c}4 \\
16 \\
\end{array}$ & $\begin{array}{l}20 \\
80 \\
\end{array}$ & $\begin{array}{c}5 \\
15 \\
\end{array}$ & $\begin{array}{l}25 \\
75 \\
\end{array}$ & $\begin{array}{l}X^{2}=0.8967 \\
P=0.96833\end{array}$ \\
\hline $\begin{array}{l}\text { Duration of surgery (hours) } \\
\text { Range } \\
\text { Mean } \pm \text { SD }\end{array}$ & & & & & $\begin{array}{l}Z=0.7737 \\
P=0.4391\end{array}$ \\
\hline
\end{tabular}

*Significant difference at $\mathrm{P}$ level $\leq 0.0$ 
Table (2): Comparison between the control and study groups in relation to core body temperature during the perioperative period

\begin{tabular}{|c|c|c|c|c|c|c|c|}
\hline \multirow{10}{*}{ 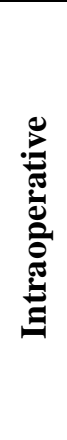 } & $0 \min$ & 20 & $36.82 \pm 0.20$ & 20 & $37.00 \pm 0.06$ & 4.1011 & $0.0000 *$ \\
\hline & $30 \mathrm{~min}$ & 20 & $36.38 \pm 0.23$ & 20 & $36.95 \pm 0.06$ & 4.8724 & $0.0000^{*}$ \\
\hline & $60 \min$ & 20 & $35.87 \pm 0.31$ & 20 & $36.87 \pm 0.09$ & 5.4822 & $0.0000^{*}$ \\
\hline & $90 \mathrm{~min}$ & 20 & $35.46 \pm 0.29$ & 20 & $36.78 \pm 0.09$ & 5.4537 & $0.0000^{*}$ \\
\hline & $120 \mathrm{~min}$ & 20 & $35.00 \pm 0.32$ & 20 & $36.72 \pm 0.08$ & 5.4591 & $0.0000 *$ \\
\hline & $150 \mathrm{~min}$ & 20 & $34.62 \pm 0.28$ & 20 & $36.65 \pm 0.07$ & 5.4778 & $0.0000^{*}$ \\
\hline & $180 \mathrm{~min}$ & 15 & $34.31 \pm 0.21$ & 20 & $36.57 \pm 0.09$ & 5.4007 & $0.0000^{*}$ \\
\hline & $210 \mathrm{~min}$ & 15 & $34.10 \pm 0.08$ & 10 & $36.30 \pm 0.06$ & 4.2283 & $0.0000^{*}$ \\
\hline & $240 \mathrm{~min}$ & 15 & $33.87 \pm 0.06$ & 7 & $36.20 \pm 0.05$ & 3.2545 & $0.0011^{*}$ \\
\hline & $270 \mathrm{~min}$ & 15 & $34.26 \pm 0.25$ & 3 & $36.10 \pm 0.06$ & 2.1213 & $0.0339^{*}$ \\
\hline \multirow{15}{*}{ 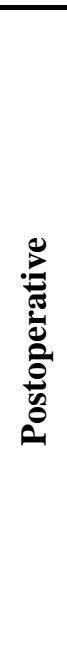 } & $15 \mathrm{~min}$ & 20 & $34.49 \pm 0.24$ & 20 & $36.56 \pm 0.12$ & 5.4649 & $0.0000^{*}$ \\
\hline & $30 \mathrm{~min}$ & 20 & $34.72 \pm 0.22$ & 20 & $36.74 \pm 0.11$ & 5.4550 & $0.0000^{*}$ \\
\hline & $45 \mathrm{~min}$ & 20 & $34.96 \pm 0.26$ & 20 & $36.89 \pm 0.09$ & 5.3878 & $0.0000^{*}$ \\
\hline & $60 \mathrm{~min}$ & 20 & $35.19 \pm 0.27$ & 16 & $37.00 \pm 0.09$ & 4.7170 & $0.0000^{*}$ \\
\hline & $75 \mathrm{~min}$ & 20 & $35.67 \pm 0.31$ & & & & \\
\hline & $90 \mathrm{~min}$ & 20 & $35.67 \pm 0.31$ & & & & \\
\hline & $105 \mathrm{~min}$ & 20 & $35.71 \pm 0.28$ & & & & \\
\hline & $120 \mathrm{~min}$ & 20 & $35.92 \pm 0.29$ & & & & \\
\hline & $135 \mathrm{~min}$ & 20 & $35.99 . \pm 0.31$ & & & & \\
\hline & $150 \mathrm{~min}$ & 19 & $36.33 \pm 0.29$ & & & & \\
\hline & $165 \mathrm{~min}$ & 19 & $36.57 \pm 0.27$ & & & & \\
\hline & $180 \mathrm{~min}$ & 17 & $36.66 \pm 0.33$ & & & & \\
\hline & $195 \mathrm{~min}$ & 14 & $36.87 \pm 0.18$ & & & & \\
\hline & $210 \mathrm{~min}$ & 10 & $37.01 \pm 0.19$ & & & & \\
\hline & $225 \mathrm{~min}$ & 5 & $37.00 \pm 0.07$ & & & & \\
\hline
\end{tabular}

*Significant difference at $\mathrm{P}$ level $\leq 0.05$

Table (3): Comparison between the control and study groups as regards time to return to base line temperature (minutes)

\begin{tabular}{|c|c|c|c|c|}
\hline & $\begin{array}{c}\text { Control group } \\
(\mathbf{N}=\mathbf{2 0})\end{array}$ & $\begin{array}{c}\text { Study group } \\
(\mathbf{N}=\mathbf{2 0})\end{array}$ & Test & $\mathbf{P}$ \\
\hline Minimum & 150 & 30 & \multirow{4}{*}{$Z=6.4337$} & \multirow{4}{*}{0.000} \\
\hline Maximum & 225 & 60 & & \\
\hline Mean & 187.50 & 45 & & \\
\hline SD & 25.78 & 13.00 & & \\
\hline
\end{tabular}

*Significant difference at $\mathrm{P}$ level $\leq 0.05$ 
Table (4): Comparison between the control and study groups as regards Post anesthesia recovery score in postoperative period

\begin{tabular}{|c|c|c|c|c|c|c|}
\hline \multirow{2}{*}{$\begin{array}{l}\text { Post anesthesia recovery score } \\
\text { in postoperative period }\end{array}$} & \multicolumn{2}{|c|}{ Control group $(\mathrm{N}=20)$} & \multicolumn{2}{|c|}{ Study group $(\mathrm{N}=20)$} & \multirow[b]{2}{*}{$X^{2}$ Test } & \multirow{2}{*}{$\mathbf{P}$} \\
\hline & n. & $\begin{array}{l}\text { Range } \\
\text { X_ SD } \\
\end{array}$ & n. & $\begin{array}{l}\text { Range } \\
\text { X_ SD }\end{array}$ & & \\
\hline $10 \mathrm{~min}$. & 20 & $\begin{array}{c}2-2 \\
2+0.0\end{array}$ & 20 & $\begin{array}{c}2-4 \\
2.50 \pm 0.89\end{array}$ & 3.804 & $0.047 *$ \\
\hline 20 min. & 20 & $\begin{array}{c}4-6 \\
5.15+0.49\end{array}$ & 20 & $\begin{array}{c}4-8 \\
5+1.21\end{array}$ & 5.3507 & $0.0188 *$ \\
\hline 30 min. & 20 & $\begin{array}{c}4-6 \\
5.33+0.95\end{array}$ & 20 & $\begin{array}{c}9-10 \\
7.40 \pm 1.14\end{array}$ & 12.536 & $0.003 *$ \\
\hline $40 \mathrm{~min}$. & 20 & $\begin{array}{c}6-8 \\
6.55 \pm 0.49\end{array}$ & -- & -- & -- & -- \\
\hline 50 min. & 20 & $\begin{array}{c}6-8 \\
6.88 \pm 1.0\end{array}$ & -- & --- & -- & -- \\
\hline $60 \mathrm{~min}$. & 20 & $\begin{array}{c}6-10 \\
7.79 \pm 1.02\end{array}$ & -- & -- & -- & -- \\
\hline 70 min. & 19 & $\begin{array}{c}6-10 \\
8.77 \pm 1.29\end{array}$ & -- & -- & -- & -- \\
\hline 80 min. & 10 & $\begin{array}{c}7-10 \\
9.39 \pm 1.17 \\
\end{array}$ & $\begin{array}{ll}-- \\
--\end{array}$ & -- & -- & -- \\
\hline 90 min. & 5 & $\begin{array}{c}9-10 \\
9.50 \pm 0.58 \\
\end{array}$ & -- & -- & -- & -- \\
\hline
\end{tabular}

*Significant difference at $\mathrm{P}$ level $\leq 0.05$

Table (5): Incidence, severity, onset, duration and frequency of shivering among the control and the study groups

\begin{tabular}{|c|c|c|c|c|c|c|}
\hline \multirow{3}{*}{$\begin{array}{l}\text { Characteristics of shivering } \\
\text { Incidence }\end{array}$} & \multicolumn{2}{|c|}{$\begin{array}{c}\text { Control group } \\
(\mathrm{N}=20)\end{array}$} & \multicolumn{2}{|c|}{ Study group $(\mathrm{N}=20)$} & \multirow{2}{*}{\multicolumn{2}{|c|}{ Statistical tests }} \\
\hline & No & $\%$ & No & $\%$ & & \\
\hline & 15 & 75 & 5 & 25 & Test & $\mathbf{P}$ \\
\hline $\begin{array}{l}\text { Severity of shivering (Score } \mathbf{0 - 3}) \\
0 \\
1 \\
2 \\
3 \\
\end{array}$ & $\begin{array}{c}5 \\
0 \\
5 \\
10\end{array}$ & $\begin{array}{c}25 \\
0 \\
25 \\
50\end{array}$ & $\begin{array}{c}15 \\
4 \\
1 \\
0\end{array}$ & $\begin{array}{c}75 \\
20 \\
5 \\
0 \\
\end{array}$ & $\mathrm{Z}=8.528$ & $0.0018 *$ \\
\hline $\begin{array}{l}\text { Onset of shivering (min) } \\
10 \\
15 \\
20 \\
30 \\
40\end{array}$ & $\begin{array}{c}\text { No }=\mathbf{1 6} \\
6 \\
1 \\
5 \\
3 \\
1\end{array}$ & $\begin{array}{c}\% \\
37.5 \\
6.25 \\
31.25 \\
18.75 \\
6.25\end{array}$ & $\begin{array}{c}\text { No }=6 \\
3 \\
2 \\
1 \\
0 \\
0\end{array}$ & $\begin{array}{c}\% \\
50 \\
33.3 \\
16.6 \\
0.00 \\
0.00\end{array}$ & \multirow[t]{2}{*}{$Z=0.9979$} & \multirow[t]{2}{*}{0.3788} \\
\hline $\begin{array}{l}\text { Range } \\
\text { Mean } \pm \text { SD }\end{array}$ & \multicolumn{2}{|c|}{$\begin{array}{c}10-40 \\
18.75 \pm 8.66\end{array}$} & \multicolumn{2}{|c|}{$\begin{array}{c}10-20 \\
15.00 \pm 4.47\end{array}$} & & \\
\hline $\begin{array}{l}\text { Duration of shivering (min) } \\
5 \\
7 \\
10 \\
12 \\
15\end{array}$ & $\begin{array}{c}\text { No }=\mathbf{1 6} \\
5 \\
0 \\
6 \\
1 \\
4\end{array}$ & $\begin{array}{c}\% \\
31.25 \\
0 \\
37.5 \\
6.25 \\
25\end{array}$ & $\begin{array}{c}\text { No }=6 \\
4 \\
2 \\
0 \\
0 \\
0\end{array}$ & $\begin{array}{c}\% \\
66.6 \\
33.4 \\
0 \\
0 \\
0\end{array}$ & \multirow[t]{2}{*}{$Z=3.4657$} & \multirow[t]{2}{*}{$0.0144^{*}$} \\
\hline $\begin{array}{l}\text { Range } \\
\text { Mean } \pm \text { SD }\end{array}$ & \multicolumn{2}{|c|}{$\begin{array}{c}5-15 \\
10.56 \pm 3.6855\end{array}$} & \multicolumn{2}{|c|}{$\begin{array}{c}5-7 \\
5.67 \pm 5.866\end{array}$} & & \\
\hline $\begin{array}{l}\text { Frequency of shivering } \\
\text { Range } \\
\text { Mean + SD }\end{array}$ & \multicolumn{2}{|c|}{$\begin{array}{c}5-9 \\
6.879 \pm 2.870\end{array}$} & \multicolumn{2}{|c|}{$\begin{array}{c}3-5 \\
3.678+0.980 \\
\end{array}$} & $Z=4.4789$ & $0.0024 *$ \\
\hline
\end{tabular}

*Significant at $\mathrm{p} \leq 0.05$ 


\section{References}

1. Stuart V, Rayborn M, Harbaugh B, Coats K. The use of an intraoperative forced air warming device alone versus warmed intravenous fluid infusion and forced air warming versus warmed intravenous fluid alone in patients undergoing open intra-abdominal surgery. Doctoral Nursing Capstone Projects. 2015. Available at http://aquila.usm.edu/dnp_capstone/22

2. Tran T, Kaneva P, Mayo E, Fried M, Feldman S. Short-stay surgery: what really happens after discharge? Surgery 2014; 156(1):20-7.

3. Mercer M. Day case surgery guidelines. Surgery 2014; 32(2):73-8.

4. Burger L, Fitzpatrick J. Prevention of inadvertent perioperative hypothermia. Br J Nurs 2009; 18: 1114, 1116-19.

5. Conway A, Kennedy W, Sutherland J. Inadvertent hypothermia after procedural sedation and analgesia in a cardiac catheterisation laboratory: a prospective observational study. J Cardiothorac Vasc Anesth 2015; 29:1285-90.

6. Liddle C. Principles of monitoring postoperative patients. Nursing Times 2013; 109(22): 24-6.

7. Polderman H. Mechanisms of action, physiological effects, and complications of hypothermia. Crit Care Med 2009; 37:S186-202.

8. Leeth D, Mamaril M, Oman S, Krumbach B. Normothermia and patient comfort: A comparative study in an outpatient surgery setting. Journal of Peri Anesthesia Nursing 2010; 25(3): 146-51.

9. Belayneh T, Gebeyehu A, Abdissa Z. Post-operative hypothermia in surgical patients at university of Gondar hospital. J Anesth Clin Res 2014; 5(11):461.
10. Kurz A. Thermal care in the perioperative period. Best Pract Res Clin Anaesthesiol 2008; 22: 39-62.

11. Kellam M, Dieckmann L, Austin P. Forced-air warming devices and the risk of surgical site infections. AORN Journal 2013; 98 (4): 354.

12. Torossian A, Brauer A, Hocker J. Preventing inadvertent perioperative hypothermia. Dtsch Arztebl Int 2015; 112: 166 .

13. Hart R, Bordes B, Hart J. Unintended perioperative hypothermia. Ochsner $\mathrm{J}$ 2011; 11(3): 259-70.

14. Sun Z, Honar H, Sessler I. Intraoperative core temperature patterns, transfusion requirement, and hospital duration in patients warmed with forced air. Anesthesiology 2015; 122: $276-85$.

15. Mohammdi E, Hasankhani H, Nighizade M. The effect of warming intravenous fluid on perioperative hemodynamic status, postoperative shivering and recovery in orthopedic surgery. Shiraz E Medical Journal 2004; 5 (3): 345-68.

16. Lewis E, Heitkemper M, Dirksen S. Medical Surgical Nursing. $6^{\text {th }}$ ed. New York: Mosby, 2004; 1855.

17. Lista F, Doherty C, Backstein M, Ahmad J. The impact of perioperative warming in an outpatient aesthetic surgery setting. Aesthetic Surgery Journal 2012; 32(5): 613-20.

18. Chue L, Moore L, Cavey A, Ashley A, Stepniewska K. Comparability of tympanic and oral mercury thermometers at high ambient temperatures. J Clin Monit 2012; 10: 91-6.

19. Phillips N. Berry \& Kohn's operating room technique. $10^{\text {th }}$ ed. New York: Mosby, 2004; 201. 
20. Holzclow B. Effects of extremely wrap to control drug induced shivering, a pilot study. Nursing Research 1990; 39 (5): 281.

21. SesslerI. Complications and treatment of mild hypothermia. American Society of Anesthesiologist 2001; 95(2). Available at: http://home.mdconsult.com.

22. Reynolds L, Beckmann J, Kurz A. Perioperative complications of hypothermia. Best Pract Res Clin Anaesthesiol 2008; 22(4):645-57.

23. Legg A, Hamer A. Forced-air patient warming blankets disrupt unidirectional airflow. Bone Joint J 2013; 95:407-10.

24. Shaw A, Steelman M, Berg J. Effectiveness of active and passive warming for the prevention of inadvertent hypothermia in patients receiving neuraxial anesthesia: a systematic review and meta-analysis of randomized controlled trials. J Clin Anesth 2017; 38:93-104.

25. Misal U, Joshi S, Shaikh M. Delayed recovery from anesthesia: A postgraduate educational review. Anesth Essays Res 2016; 10(2): 16472.
26. Jie Y, Yongjing L, Shiyuan X, Yongyu S, Intraoperative hypothermia and its clinical outcomes in patients undergoing general anesthesia. PLoS One 2017; 12(6): 7221.

27. Smith I, Newson D, White F .Use of forced -air warming during \&after outpatient arthroscopy surgery. Anesth Analg 1994; 87: 836 -41.

28. Kiekkas P, Pouiopoulou M, Papahatzi A, Souleles P. Effects of hypothermia and on standard PACU monitoring of patients. AANA J 2005; 73(1): 47-53.

29. Sultan P, Habib A, Cho Y. Carvalho B. The Effect of patient warming during Caesarean delivery on maternal and neonatal outcomes. British Journal of Anaesthesia 2015; 115 (4): 500-10.

30. Yossef A. Does hypothermia have any effect on perioperative blood loss and resection time or cardiac morbidity during TURP surgery? Unpublished Master Thesis, Faculty of Medicine, Alexandria University, 2006.

31. Poveda V,Galvao C. Hypothermia in the intraoperative period: can it be avoided? 2011. Available at: http://dx.doi.org/10.1590/S008062342011000200016. 